\title{
Management of patients with adrenal cancer: recommendations of an international consensus conference
}

\author{
D E Schteingart, G M Doherty ${ }^{1}$, P G Gauger ${ }^{1}$, T J Giordano², G D Hammer, \\ $M$ Korobkin ${ }^{3}$ and $F$ P Worden
}

Departments of Internal Medicine, Surgery ${ }^{1}$, Pathology ${ }^{2}$ and Radiology ${ }^{3}$, University of Michigan Medical School, Ann Arbor, Michigan, USA

(Requests for offprints should be addressed to D E Schteingart; Email: dschtein @umich.edu)

\begin{abstract}
Adrenocortical carcinomas are rare, highly malignant tumors that account for only $0.2 \%$ of deaths due to cancer. Given the limited number of patients seen in most medical centers with this diagnosis, series usually reported are small and clinical trials not randomized or blinded. In an attempt to answer important questions concerning the management of patients with adrenal cancer, a consensus conference was organized and held at the University of Michigan in Ann Arbor, MI, 11-13 September 2003, with the participation of an international group of physicians who had reported on the largest series of patients with this disease and who had recognized basic and clinical research expertise in adrenal cortical cancer. Totally 43 questions were addressed by the presenters and recommendations discussed in plenary and breakout sessions. Evidence for the recommendations of this conference was at the $2-4+$ level and based on available literature and participants' experience.

In addition to setting up guidelines in specific areas of the diagnosis and treatment of adrenal cancer, the conference recommended and initiated the planning of an international prospective trial for treatment of patients with adrenal cancer in stages III and IV. In terms of new therapies, first trials of dendritic cell therapy in human subjects with adrenal cancer have been started, but it is too early to comment on efficacy. Different strategies of immunotherapy, including DNA vaccination are currently being tried in animal models. There are no clinical gene therapy trials for human adrenal cortical cancer. The adrenals are a preferred target for adenovirus and the results of gene therapy in preclinical studies are promising. In addition, there is evidence that histone deacetylase inhibitors can further enhance the rate of adenoviral infectivity in human adrenal cancer cells. Testing of retroviral vectors, non-viral vectors, small interfering RNA technology, and combined approaches could be performed in various laboratories. Anti-angiogenic substances have only been applied in preclinical studies. The use of these and other agents in the treatment of adrenal cancer should be hypothesis-driven and based on a thorough analysis of tumor biology.
\end{abstract}

Endocrine-Related Cancer (2005) 12 667-680

\section{Introduction}

Adrenocortical carcinomas (ACCs) are rare, highly malignant tumors that account for only $0.2 \%$ of deaths due to cancer. Their incidence has been estimated at 2 per million people per year. Approximately $50 \%$ of these tumors are functioning and produce hormonal and metabolic syndromes leading to their discovery. The other $50 \%$ are silent and discovered only when they attain a large size and produce localized abdominal symptoms or metastases. Occasionally children have been found to have ACC but most cases occur between ages 30 and 50 (Brennan 1987). An exception to this age distribution occurs in southern Brazil, where the annual incidence of ACC in children is unusually high, ranging from 3.4 to $4.2 /$ million children, compared with a worldwide incidence of 0.3 /million children younger than 15 (Figueiredo et al. 1999). The etiology 
of adrenal cancer is unknown but molecular cytogenetic cloning studies in the past 5 years have described chromosomal abnormalities possibly associated with tumorigenesis (Lynch et al. 1985, Grayson et al. 1994, Lin et al. 1994, Reincke et al. 1994, Miyamoto et al. 1996, McNicol et al. 1997, Bornstein et al. 1999). While genetic defects may predispose to adrenal cortical tumor formation, environmental factors have been implicated in southern Brazil because the distribution of the tumors follows a regional rather than familial pattern.

There are multiple publications on the diagnosis and management of patients with ACC However, there is no validation or evidence-based consensus on the diagnosis, prognosis and management of patients with this disease. Given the limited number of patients seen in most medical centers with this diagnosis, the series usually reported are small and clinical trials not randomized or blinded. In an attempt to answer important questions concerning the management of patients with adrenal cancer, a consensus conference was organized and held at the University of Michigan in Ann Arbor, MI, 11-13 September, 2003, with the participation of an international group of physicians who had reported on the largest series of patients with this disease and who had recognized basic and clinical research expertise in ACC. This report summarizes the main recommendations made during this conference.

\section{Method}

A list of questions was prepared and mailed to all invited participants for evaluation. Questions were modified or reformulated and additional questions added. The final questions were grouped into ten major categories as follows: (i) diagnosis; (ii) prognosis; (iii) surgical treatment; (iv) adjuvant therapy; (v) radiation therapy; (vi) emergent therapies; (vii) follow-up during treatment; (viii) adrenal cancer in children; (ix) metastatic disease; and $(\mathrm{x})$ data collection.

\section{Data collection}

A literature review was carried out and relevant articles that reported on series of patients (not single case reports) were listed. These articles addressed the topics covered by the questions. Articles were assembled on a $\mathrm{CD}$ and mailed to all participants in anticipation of the conference. All participants were assigned a topic for discussion and were expected to specifically answer each question pertinent to the topic. Two or three participants were asked to address the same topic and questions. Presentations were limited to $20 \mathrm{~min}$ and time was allowed for general discussion. Each day included breakout sessions at which participants were asked to formulate a consensus on the questions asked. This consensus became the conference preliminary recommendations. Final recommendations were agreed upon at a final plenary session.

\section{Participants and program}

The names of participants, their country of origin and topic covered are summarized in Table 1. The moderators and discussants for each section are listed with each category of questions.

\section{Consensus recommendations}

We summarize below the topics discussed by the conference and its recommendations. The recommendations are based on the assumption that upon suspicion of ACC, patients are referred to a medical center with appropriate expertise with this disease. The objective is to achieve definitive diagnosis including endocrinological and oncological staging and definitive initial surgery (open adrenalectomy) with curative intent. Evidence for the recommendations of this conference was based on available literature of nonrandomized or observational studies and expert opinion of participants (evidence level 2-4+). References providing the background for discussion and recommendations are listed for each set of topics and when available, references are indicated for a particular one. Each session in which a specific set of topics was discussed had two moderators and two or three discussants.

\section{Diagnosis}

Moderators: Melvyn Korobkin, Milton Gross

Lead Discussants: Franco Mantero, Martin Reincke, Oscar Bruno

\section{Determination if a unilateral adrenal mass is cancer in a patient without known primary tumor (Arteaga et al. 1984, Copeland 1984, Farge et al. 1987, Grondal \& Curstedt 1991, Schteingart 1992, 2000)}

The suspicion of ACC is raised by a combination of clinical, biochemical and radiological criteria and finally verified by histopathology. Approximately $50 \%$ of ACCs are functional, and Cushing's syndrome with virilization is the most frequent presentation.

The mean tumor size of ACC is $10 \mathrm{~cm} ; 95 \%$ of ACC are larger than $5 \mathrm{~cm}$. The prevalence of ACC in surgical series of adrenal incidentalomas is $2 \%$ in tumors 
Table 1 Participants in the International Consensus Conference

\begin{tabular}{|c|c|c|c|}
\hline Name & Specialty & Affiliation & City/Country \\
\hline Ahlman, Hakan, MD. & Surgery & Goteborg University & Goteborg, Sweden \\
\hline Aron, David, MD, MS & Epidemiology & Education Office & Cleveland, OH, USA \\
\hline Barson, Luisa, MD & Histology, microbiology & University of Padova & Padua, Italy \\
\hline Ben Josef, Edgar, MD & Radiology & University of Michigan & Ann Arbor, MI, USA \\
\hline Beuschlein, Felix, MD & Endocrinology & Albert Ludwigs University & Freiburg, Germany \\
\hline Bornstein, Stefan, MD & Endocrinology & University of Dusseldorf & Dusselborf, Germany \\
\hline Bertagna, Xavier, MD & Endocrinology & Hop Cochin & Paris, France \\
\hline Bruno, Oscar, MD & Endocrinology & University of Buenos Aires & Buenos Aires, Argentina \\
\hline Campbell, Karen, MS & Molecular biology & $\begin{array}{l}\text { Cushing Support \& } \\
\text { Research Foundation }\end{array}$ & Pleasanton, CA, USA \\
\hline Chrousos, George, MD & Endocrinology & $\mathrm{NICHD}, \mathrm{NIH}$ & Bethesda, MD, USA \\
\hline Doherty, Gerard, MD & Endocrine surgery & University of Michigan & Ann Arbor, MI, USA \\
\hline Fassnacht, Martin, MD & Internal medicine & University of Wuerzburg & Wuerzburg, Germany \\
\hline Fojo, Antonio, MD & Oncology & $\mathrm{NCl}, \mathrm{NIH}$ & Bethesda, MD, USA \\
\hline Gauger, Paul, MD & Endocrine surgery & University of Michigan & Ann Arbor, MI, USA \\
\hline Giordano, Thomas, MD, PhD. & Pathology & University of Michigan & Ann Arbor, MI, USA \\
\hline Grekin, Roger, MD & Endocrinology & University of Michigan & Ann Arbor, MI, USA \\
\hline Gross, Milton, MD & Nuclear medicine & University of Michigan & Ann Arbor, MI, USA \\
\hline Hammer, Gary, MD, PhD & Endocrinology & University of Michigan & Ann Arbor, MI, USA \\
\hline Kandeel, Fuad, MD, PhD & Endocrinology & City of Hope National Medical Center & Duarte, CA, USA \\
\hline Kasperlik-Zaluska, Anna, MD & Endocrinology & Bielanski Hospital & Warsaw, Poland \\
\hline Kirschner, Lawrence, MD, PhD & Endocrinology & Ohio State University & Columbus, OH, USA \\
\hline Korobkin, Melvyn, MD & Radiology & University of Michigan & Ann Arbor, MI, USA \\
\hline Koch, Christian, MD & Endocrinology & $\mathrm{NICHD}, \mathrm{NIH}$ & Bethesda, MD, USA \\
\hline Kudelka, Andrzej, MD & $\begin{array}{l}\text { Gynecology/medical } \\
\text { oncology }\end{array}$ & $\begin{array}{l}\text { University of Texas, } \\
\text { MD Anderson }\end{array}$ & Houston, TX, USA \\
\hline Lacroix, Andre, MD & Endocrinology & CHUM University of Montreal & Montreal, Canada \\
\hline Latronico Ana, MD & Pediatric endocrinology & University of Sao Paulo & Ribeirao Preto, Brazil \\
\hline Mantero, Franco, MD & Endocrinology & University of Padova & Padua, Italy \\
\hline Montie, James, MD & Urology & University of Michigan & Ann Arbor, MI, USA \\
\hline Norton, Jeffrey, MD & Surgical oncology & Stanford Cancer Center & Stanford, CA, USA \\
\hline Reincke, Martin, MD & Endocrinology & University of Freiburg & Freiburg, Germany \\
\hline Ribeiro, Raul, MD, PhD & Pediatric endocrinology & St Jude Children's Hospital & Memphis, TN, USA \\
\hline Schteingart, David, MD & Endocrinology & University of Michigan & Ann Arbor, MI, USA \\
\hline Shulkin, Barry, MD & Nuclear medicine & University of Michigan & Ann Arbor, MI, USA \\
\hline Skogseid, Britt, MD & Endocrinology & University of Uppsala & Upssala, Sweden \\
\hline Starkman, Monica, MD & Psychiatry & University of Michigan & Ann Arbor, MI, USA \\
\hline Stratakis, Constantine, MD, PhD & Genetics/endocrinology & $\mathrm{NICHD}, \mathrm{NIH}$ & Bethesda, MD, USA \\
\hline Terzolo, Massimo, MD & Internal medicine & University of Turin & Orbassano, Italy \\
\hline Thompson, Norman, MD & Endocrine surgery & University of Michigan & Ann Arbor, MI, USA \\
\hline Vassilopoulou-Sellin, Rena, MD & Endocrine oncology & $\begin{array}{l}\text { University of Texas, MD } \\
\text { Anderson Cancer Center }\end{array}$ & Houston, TX, USA \\
\hline Worden, Francis, MD & Oncology & University of Michigan & Ann Arbor, MI, USA \\
\hline Wolf, Stuart, MD & Urology & University of Michigan & Ann Arbor, MI, USA \\
\hline
\end{tabular}

$<4 \mathrm{~cm}, 6 \%$ in tumors $4-6 \mathrm{~cm}$, and $25 \%$ in tumors with a diameter $>6 \mathrm{~cm}$.

Imaging criteria indicating a high probability of adrenal adenoma have been defined for computed tomography (CT), magnetic resonance imaging (MRI), NP-59 scintigraphy and fluorodeoxyglucose (FDG) positron emission tomography (FDG-PET) (Hamper et al. 1987, Gross et al. 1988, Smith et al. 1989, Leshinen Kallio 1994, Korobkin et al. 1995, Juhlin et al. 1998, Yasuda et al. 2000, Yun et al. 2001).
The number of patients with ACC in imaging studies has been limited. Direct comparison of different imaging techniques for ACC is not available. Current criteria suggestive of a benign adenoma include attenuation values (expressed as Hounsefield Units) $<10 \mathrm{HU}$ on unenhanced CT, $<30 \mathrm{HU}$ on enhanced scans. Tumors with $>10 \mathrm{HU}$ include lipid-poor adenomas, pheochromocytomas, metastasis and ACC. Most of the data indicate that a 15 min delayed CT wash-out greater than $60 \%$ is suggestive of adenoma. 
There is no evidence suggesting that $\mathrm{MRI}$ is superior to CT. MRI criteria for ACC are heterogeneous signal intensity on $\mathrm{T} 1$ and $\mathrm{T} 2$, peripheral nodular enhancement and central hypoperfusion on contrast MRI. MRI should be performed in large tumors prior to surgery to assess vascular invasion. Sensitivity, specificity, positive predictive value and negative predictive value for CT and MRI are around $90 \%$.

Data for FDG-PET and adrenal scintigraphy are promising. Neither technique is widely available. Owing to the limited experience and high costs, FDG-PET is currently not routinely recommended.

\section{Indication for fine needle biopsy (FNB) (Gaboardi et al. 1991)}

FNB is currently not indicated for the diagnosis of primary ACC because of poor differentiation from adenoma and the possibility that capsular breach could cause spillage of tumor cells into the surrounding tissues along the path of the needle.

FNB is indicated only in patients with a history of other cancers (particularly lung, breast, kidney), no signs of other metastases, and a heterogeneous mass with a high unenhanced attenuation value $(>20 \mathrm{HU})$ after exclusion of pheochromocytoma.

\section{Positive predictive value of histological and molecular markers (Weiss 1984, Cibas et al. 1990, Medeiros \& Weiss 1991, Fetsch et al. 1999)}

Histopathological assessment should follow current guidelines. ACC should be suspected in tumors with a Weiss score $>2$.

Histological algorithms, such as those of Weiss, Hough and van Sloten, have high negative and positive predictive values for the diagnosis of ACC. According to these criteria, a Weiss score (0-9) was determined for each patient, according to the presence or absence of the following nine histological features: (i) high mitotic rate; (ii) atypical mitoses; (iii) high nuclear grade; (iv) low percentage of clear cells; (v) necrosis; (vi) diffuse architecture of tumor; (vii) capsular invasion; (viii) sinusoidal invasion; and (ix) venous invasion. The three most commonly found are a mitotic rate greater than 5 per 50 High Power Field (HPF), atypical mitotic figures and venous invasion. The mitotic rate is an important criterion not only for distinguishing malignant from benign tumors but also for predicting clinical virulence of ACCs. Patients with carcinomas with a high mitotic rate (more than 20 mitoses per $40 \mathrm{HPF}$ ) have a shorter disease-free survival period as compared with those with low mitotic rates (less than 20 mitoses per $40 \mathrm{HPF}$ ).

Immunohistochemical markers, such as Ki67, are additionally helpful to confirm malignancy and, like D11, melan A and chromogranin A to define or exclude the adrenocortical origin of the tumor. Molecular markers are promising new tools for the diagnosis of ACC and may predict prognosis. To date, the data are preliminary, and cannot be recommended for routine use.

\section{Value of the four-stage MacFarlane classification modified by Sullivan (MacFarlane 1958, Sullivan 1978)}

The McFarlane classification provides a useful staging system which allows pre-operative stratification of the patients and predicts prognosis. Table 2 shows the MacFarlane classification as currently framed.

However, the prognosis of ACC patients with stage I and II disease is not different. This has suggested the need for a different staging classification. The modification proposed by Icard (1992) and Lee (1995) suggests restricting stage IV disease to patients with distant metastases. In addition, stage III could be subcategorized as local or regional.

The McFarlane/Sullivan classification should be revised to include more precise prognostic implications.

Table 2 The MacFarlance classification as currently framed

\begin{tabular}{lccccc}
\hline Stage & Size & $\begin{array}{c}\text { Lymph } \\
\text { nodes }\end{array}$ & $\begin{array}{c}\text { Local } \\
\text { invasion }\end{array}$ & Metastases & TNM \\
\hline I & $<5 \mathrm{~cm}$ & - & - & - & $\mathrm{T}_{1} \mathrm{~N}_{0} \mathrm{M}_{0}$ \\
II & $>5 \mathrm{~cm}$ & - & - & - & $\mathrm{T}_{2} \mathrm{~N}_{0} \mathrm{M}_{0}$ \\
III & Any size & + & + & - & $\mathrm{T}_{1,2} \mathrm{~N}_{1} \mathrm{M}_{0}$ \\
IV & Any size & + & + & + & $\mathrm{T}_{1,2} \mathrm{~N}_{1} \mathrm{M}_{1}$ \\
\hline
\end{tabular}

Prognosis (Bradley 1975, King \& Lack 1979, Hogan 1980, Didolkar et al. 1981, Thompson 1983, Bodie et al. 1989, Venkatesh et al. 1989, Luton et al. 1990, Kasperlik-Zaluska 1994, 1995, Wajchenberg et al. 2000, Schteingart \& Homan 2001)

Moderators: Gerard Doherty, Thomas Giordano Lead Discussants: Xavier Bertagna, Luisa Barzon, Andrezj Kudelka 
Recommended criteria for determining prognosis (Weiss et al. 1988)

Size of tumor (largest diameter on CT or MRI) gives an estimate of tumor burden. A large tumor burden $(>12 \mathrm{~cm})$ is associated with poor prognosis. Localized disease at diagnosis and complete tumor resection at any stage offers the best prognostic advantage, since no effective medical therapy is available for ACC.

Histological and molecular markers of cell proliferation may predict tumor behavior.

Clinically and/or histologically oriented parameters (gender, age, tumor secretory status) are clearly secondchoice predictors that are often also described. It is possible that older age and cortisol or aldosterone hypersecretion contribute to unfavorable prognosis, whereas androgen hypersecretion may be associated with a more favorable outcome. Non-functioning tumors have been associated with longer survival in some series.

Relative value of histology, molecular markers, stage of the disease for determining prognosis (Weiss 1984, Cibas et al. 1990, Medeiros \& Weiss 1991, Fetsch et al. 1999)

Precise tumor pathological examination by expert pathologists provides some highly reliable prognostic factors; among them a Weiss score $>3$ or mitotic index $>6 / 10$ HPF (intratumoral hemorrhage or necrosis and lymph-vascular invasion are independent prognostic factors).

A number of molecular markers have been studied that are associated with malignancy. Among them, IGF-II overexpression, Uniparental Paternal Disomy (UPD) for 11p15, Loss of Heterozygosity (LOH) for $17 \mathrm{p} 13$ and Topoisomerase (TOP)2A overexpression, are particularly promising as independent markers for malignancy. However, for most of the markers, their prognostic value has not been validated in prospective studies. In one study, $\mathrm{LOH}$ at $17 \mathrm{p} 13$ was shown to be an independent predictor of tumor recurrence after 'curative' surgery of stage I/II tumors.

Staging is the most important and better-validated prognostic factor. It requires thorough assessment at surgery to identify stage (I, II, III), as well as the modern imaging studies that can be performed preoperatively (CT, MRI, PET scan) to identify or rule out distant metastases (stage IV).

\section{Way of predicting patients who will have aggressive disease from those in whom the disease will follow an indolent course (Bradley 1975, Hogan 1980)}

Tumor staging and pathological features are the best predictors of disease outcome.
Molecular markers are associated with aggressive tumor phenotype, but further studies are needed to assess their prognostic value and utility to predict responsiveness to therapy.

\section{How does prognosis affect choice of therapy: chemotherapy, surgery, radiation (Bradley 1975, King \& Lack 1979, Hogan 1980, Thompson 1983, Bodie et al. 1989, Luton et al. 1990, Dickstein et al. 1999)}

Patients with presumed stage I/II tumors will always be offered surgery. Following tumor removal at first operation, a definite staging should be assessed, as well as detailed pathological assessment of the tumor (Weiss score, mitotic index).

In the case of residual tumor, further local-radiofrequency ablation (RFA), irradiation or systemic (chemotherapy) should be considered.

In the case of 'complete' resection, the recurrence risk should be assessed (Weiss score, mitotic index); follow-up is mandatory and adjuvant therapy (mitotane, irradiation) can be considered but its value still needs to be validated.

Surgical resection should be considered for relapses in highly selected patients with excellent performance status and symptomatic (i.e. from hormone hypersecretion), loco-regional recurrence or isolated distant metastases if complete resection can be achieved.

Surgical resection is rarely indicated if there is a probability of only incomplete resection or in the presence of unresectable, distant metastatic disease.

Adjuvant mitotane may not improve disease-free and overall survival in ACC, but there are reports indicating that early administration of mitotane after surgery may improve overall survival. Definitive studies are lacking.

Mitotane may lead to tumor regression in some cases of stage III/IV disease. New chemotherapy protocols based on tumor biology are needed. Radiation can be palliative for bone metastases.

\section{Assessment of prognosis and selection of further therapy when first and second-line therapy fail}

Complete tumor resectability should always be assessed. Resectability of recurrent tumor masses is the feature associated with better prognosis after primary therapy fails.

The patient's age does not influence prognosis, even though longer survival in younger patients has been reported. 
Further medical therapy should be based on tumor biology. No reliable molecular markers are yet available, but progress should come from new techniques aimed at assessing the 'molecular signature' of a given tumor. It could improve our ability to predict: (i) survival; (ii) risk of recurrence after 'complete surgical removal'; and (iii) the eventual response to chemotherapy.

\section{Surgical treatment (Thompson 1983, Bodie et al. 1989, Jensen et al. 1991, lcard et al. 1992, 2001, Pomier \& Brennan 1992 , Schteingart 1992, Bellantone et al. 1997, Peix et al. 1998, Munver et al. 2003)}

Moderators: Norman Thompson, James Montie

Lead Discussants: Hakan Ahlman, Jeff Norton

\section{Place for laparoscopic surgery in the resection of primary malignant lesions}

There is no role for laparoscopic removal of a known or likely ACC but there is controversy on the role of laparoscopic removal of indeterminate incidentalomas that could admittedly be small ACCs.

While the benefits of laparoscopic adrenalectomy are clear, and will be provided to many patients, the negative influence of laparoscopic surgery for ACC is not yet fully appreciated and will potentially affect few patients.

\section{Selection of patients with an indeterminate incidentally discovered adrenal mass for laparoscopic or open adrenalectomy}

Consideration should be given to the recommendations of the NIH State of the Science Conference on the Adrenal Incidentaloma:

- Remove by an anterior approach any lesion $>6 \mathrm{~cm}$ or with clear imaging characteristics of malignancy (indistinct borders/unclear relationship to surrounding organs/obliteration of fat planes), unenhanced density $>10 \mathrm{HU}$ (relative), 15 min delayed enhancement washout $<60 \%$, absence of signal intensity loss on out-of-phase MRI or non-visualization on NP-59 (if available).

- Consider a laparoscopic approach for resection of 4-6 cm lesions if there are no suspicious imaging characteristics.

- Convert from the laparoscopic to the open approach if there is any evidence of malignancy at exploration, including local invasion or metastasis.

\section{Extent of surgical approach}

One should plan a feasible operation to provide for gross total removal without capsular breach. For patients in stages II and III, concomitant resection of kidney, liver, spleen, pancreas, stomach, colon and wall of the vena cava should be considered if indicated because of direct tumor extension to those structures, if it is feasible and safe.

The threshold for en bloc resection of the kidney should be low for any patient in whom there is a concern about involvement of the renal capsule or renal vein.

\section{Indication of surgery for resection of metastatic disease (stage IV)}

If complete resection of primary and metastases is feasible at initial operation, it should be done (even if done in two stages). If it is anticipated that $>90 \%$ of the tumor burden can be removed, an operation should be considered. However, there are no convincing data to indicate what percent of tumor burden needs to be removed in order to make surgery worthwhile.

If debulking would amount to limited tumor removal, it should not be done, unless it will clearly palliate a severe hormonal syndrome or facilitate successful RFA.

Indicators of tumor biology (e.g. long disease-free interval, slow progression) should be used to individualize decisions. Histological indicators of tumor malignancy (low grade vs high grade) could be considered in making individual decisions but definitive data are lacking.

\section{Adjuvant therapy (Martz \& Straw 1977, Bates et al. 1991, VanSeters \& Moolenaar 1991, Pomier \& Brennan 1992, Schteingart et al. 1993, Vassilopoulou-Sellin et al. 1993, Wooten \& King 1993, Haak et al. 1994, Kasperlik-Zaluska 1994, Cai et al. 1995, Pinerio-Sanchez et al. 1995, Terzolo et al. 2000, Munver et al. 2003)}

Moderators: David Schteingart and Frank Worden Lead Discussants: Rena Vassilopoulou Sellin, Anna Kasperlik-Zaluska

Treatment of patients in stages I and II: surgery alone or surgery plus adjuvant chemotherapy (Kasperlik-Zaluska 1994, Percarpio \& Knowlton 1976)

The benefit of adjuvant therapy has not been established. However, published reports suggest benefit 
of low-dose mitotane therapy following surgery for primary tumor. Prospective, randomized clinical trials are recommended (see below). Malignancy grade should not determine use of adjuvant treatment because treatment may be effective in low grade or high grade malignancy.

\section{Types of drugs to use; mitotane vs other drugs}

There is no well-controlled head-to-head comparison studies of mitotane and other drugs used as adjuvant therapy. There is a need to perform prospective, randomized trials with mitotane first and to select additional agents for study afterwards.

\section{Prediction of response to mitotane from in vitro assays (Martz \& Straw 1977, Schteingart et al. 1993, Cai et al. 1995, Pineiro-Sanchez et al. 1995)}

There is the potential use of tests such as a tritium release assay to determine the ability of tumor tissue to metabolize mitotane. The ability to metabolize mitotane and covalently bind the metabolite may determine the adrenalytic effect of the drug. However, there are no definitive clinical studies to determine if this test can predict response. Prospective studies of this type could help answer this question.

\section{Utility of mitotane levels in following patients on adjuvant therapy (VanSeters \& Moolenaar 1991, Haak et al. 1994, Terzolo et al. 2000)}

Mitotane levels should be obtained during treatment and dose should aim for levels of $14-20 \mu \mathrm{g} / \mathrm{dl}$ if tolerated (see guidelines for mitotane use below).

Since mitotane needs to be metabolized for adrenalytic activity, measurement of urinary metabolites could be used in assessing the therapeutic dose. However, there are no studies to confirm the utility of such measurements.

\section{Guidelines for mitotane use (Haak et al. 1994)}

The usually tolerated dose is $3.0-4.0 \mathrm{~g} /$ day. However, use serum levels and patient tolerance to determine optimal dose. Aim for 2 years but treat longer if patient is doing well.

A recommended protocol for mitotane use is as follows:

- Begin with $2 \mathrm{~g}$ /day and advance to achieve serum levels of $14-20 \mu \mathrm{g} / \mathrm{dl}$ (4-6 g/day). The target blood level may be unattainable because of side effects, in which case one should adjust the dose to tolerance.
- Monitor patients clinically and by measuring adrenocorticotropin (ACTH)/Urinary free cortisol (UFC)/ electrolytes.

- Adjust the dose of cortisol replacement to assure adequate adrenal replacement. Patients may need a higher dose of cortisol if they present with gastrointestinal side effects.

- Monitor and correct as needed thyroid function, serum testosterone and lipids.

- Provide vigorous anti-emetics/other support.

\section{A role for non-mitotane-based adjuvant regimens?}

There are no data to support a specific protocol. Consideration should be given to a co-operative, multicenter clinical trial:

- Prospective, randomized, two- (or three-) arm trial depending on size calculations.

- Surgery alone vs surgery + mitotane (vs surgery+ mitotane + streptozotocin).

- Active therapy for 2 years, then follow-up for 2-3 years.

- Primary outcome: time to first recurrence.

- Assume $50 \%$ recurrence in 2 years; calculate trial size for $50 \%$ improvement with adjuvant therapy.

\section{Radiation therapy (Percarpio \& Knowlton 1976, Magee et al. 1987, Haak et al. 1994, Wood et al. 2003)}

Moderator: Melvyn Korobkin, Barry Shulkin

Lead Discussants: Edgar Ben Josef, Antonio Fojo

\section{Indications for local radiation therapy: (i) after initial tumor resection and (ii) after local tumor recurrence post-surgery}

There are very few data in the medical literature documenting efficacy of radiation therapy in ACC. Limited available data and anecdotal reports suggest that radiation therapy is probably as effective in ACC as in the majority of other solid tumors. As with other solid tumors, radiation therapy is recommended in the treatment of bone, brain and other metastases. Radiation therapy is also recommended in the treatment of symptomatic local recurrences.

While in other solid tumors radiation therapy is routinely recommended to provide local control, the use of radiotherapy for asymptomatic, unresectable local recurrences is controversial. The risk/benefit ratio should be individually assessed. 
Radiation treatment of the adrenal bed can be administered to a patient with an incomplete local resection or after a local recurrence. The latter should not replace surgery, especially in a patient without evidence of other sites of disease, but rather, could be used post-operatively as an adjunct to surgery.

\section{Efficacy of Radio Frequency Ablation (RFA) of local recurrence or hepatic metastases (Haak et al. 1994, Wood et al. 2003)}

RFA offers an alternative to surgery in some patients with metastatic adrenocortical cancer but its utility and value remain to be proven.

RFA can be considered in the treatment of lesions less than $5-6 \mathrm{~cm}$ in size that are not near indispensable tissues or large blood vessels.

\section{Metastatic disease (Hogan 1980, Nader et al. 1983, Johnson \& Greco 1986, Brennan 1987, Bodie et al. 1989, Luton et al. 1990, Pomier \& Brennan 1992, Schteingart 1992, Schlumberger et al. 1995, Beruti et al. 1998, Khan et al. 2000, Williamson et al. 2000)}

Moderators: Frank Worden, Barry Shulkin Lead Discussants: Martin Fassnacht, Britt Skogseid, Massimo Terzolo

\section{Role of FNB and PET in evaluating metastatic lesions}

In general, FNB is not needed. Because of its wide availability and physical characteristics, FDG is currently the best PET tracer to evaluate ACC. Sensitivity and specificity still need to be evaluated in a larger cohort of patients with adrenal tumors.

Adrenocortical-specific tracers (metomidate) are under investigation for clinical practice.

\section{Regimens that should be offered as first-line therapy}

The evidence regarding efficacy of first-line therapy is very limited (level C). Possible protocols are:

- Etoposide + doxorubicin + cisplatin + mitotane

- Streptozotocin + mitotane

- Mitotane alone or platin + etoposide + mitotane

All protocols with mitotane should also include replacement with cortisol and fludrocortisone (if aldosterone deficiency is evident).

\section{Regimens that should be offered as second- line therapy}

Regimens that should be offered as second-line therapy are: (i) treatment not used as first-line; and (ii) those not validated by controlled studies (limited studies or anecdotal responses): streptozotocin + mitotane, taxotere + gemcitabine, taxol + doxorubicin .

\section{Emerging therapies}

\section{Influence of tumor biology on therapy}

Moderators: Thomas Giordano, Gary Hammer Lead Discussants: Constantine Stratakis, Lawrence Kirschner

\section{Role of gene array data in determining clinical behavior of adrenal cancer}

There is a potential role for gene array data to be used in predicting behavior, prognosis, choice of and response to therapy. This is based on recent preliminary data that identified certain signaling pathways are highly correlated with histology of the tumor (e.g. IGF-II). This should be pursued by: (i) development of quality resources through multinstitutional programs but centralized through main referral centers database coordination; (ii) ensuring the quality of the collected tissue and its processing; and (iii) development of molecular criteria that will group tumors into diagnostic groups and the software that will take these into account.

Role of secreted factors (ACTH, corticotropinreleasing hormone, IGF-II, inhibin, etc) in the development and growth of adrenal carcinoma

IGF-II is the leading growth factor associated with malignancy in adrenocortical tissue, but its causal association with other prognostic factors (metastasis, response to treatment) is not known but probable.

The differential effects of ACTH vs additional proopiomelanocortin (POMC)-derived peptides (e.g. $\mathrm{N}$-terminal fragment of POMC) on adrenocortical tissue is an area of active research.

There are no good data for other secreted factors and their respective signaling pathways and their effect on prognosis and management, although currently they are under intense investigation.

Recent microarray and secreted factor data have not been applied in treatment decisions. However, microarray data looking at particular signaling pathways hold great potential for target identification and in the future, determining response to treatment. This technology will eventually lead to the development of 
specifically designed therapies tailored to each tumor's (or tumor group) molecular signature.

\section{New therapies}

Moderators: Frank Worden, Gary Hammer

Lead Discussants: Stefan Bornstein, Tito Fojo, Felix Beuschlein

\section{New chemotherapeutic drugs: available protocols and response}

There are no controlled clinical trials with new chemotherapeutic agents for adrenocortical cancer. Studies involve small case series, single-patient trials and anecdotal unpublished communications. Compounds that have been used include established chemotherapeutic agents for treatment of other solid tumors, as well as more recent compounds, used in single cases. These agents include streptozotocin, gemcitabine, navelbine, docetaxel and taxol. The best evidence is for streptozotocin. However, available evidence does not allow for any conclusions on the efficacy of these agents in ACC.

\section{Prospects for immunotherapy and gene therapy}

Tumor immunotherapy with dendritic cells is currently used in a variety of human cancers. This therapy holds promise, but it is still experimental. First trials in humans with adrenal cancer applying dendritic cell therapy have been started, but it is too early to comment on efficacy. Different strategies of immunotherapy, including DNA vaccination are currently being tried in animal models.

There are no clinical gene therapy trials for human adrenal cortical cancer. There are studies using different approaches of cytotoxic adenoviral gene therapy in human adrenocortical cancer cells in vitro and in human adrenal cancer xenografts in mice. The adrenals are a preferred target for the adenovirus and the results in preclinical studies are promising. In addition, there is evidence that Histone deacetylase (HDAC) inhibitors can further enhance the rate of adenoviral infectivity in human adrenal cancer cells.

Testing of retroviral vectors, non-viral vectors, Small interfering RNA (siRNA) technology and combined approaches could be performed in various laboratories.

\section{Role of anti-angiogenic drugs, small molecules and antibody strategies}

There is currently a multicenter trial employing gefitinib (Iressa), which inhibits the intracellular phos phorylation of numerous tyrosine kinases associated with the epidermal growth factor receptor. There have been single trials with thalidomide. Anti-angiogenic substances have only been applied in preclinical studies.

Systematic testing of small molecule therapies (e.g. tyrosine kinase inhibitors) on adrenal cortical cancer cell lines may be attempted in collaboration with pharmaceutical companies. The use of these and other agents in adrenocortical cancer should be hypothesisdriven and based on a thorough analysis of adrenocortical tumor biology.

\section{Follow-up of patients during treatment (Schteingart et al. 1966, Contreras et al. 1985, La Rocca et al. 1990)}

Moderators: David Schteingart, Melvyn Korobkin Lead Discussants: Andre Lacroix, Fuad Kandeel, Christian Koch

\section{Follow-up of patients after initial surgery}

\section{Immediate post-operative care}

Required for hormone-secreting tumors. Hypothalamic-pituitary-adrenal axis function should be evaluated to assure adequate glucocorticoid replacement status.

The tumor hormone profile should be re-evaluated to assess the completeness of surgical resection. Treatment should be adjusted for related co-morbid conditions such as diabetes mellitus, hypertension, hypercoagulable state, etc. Appropriate therapies should be instituted in order to restore physiological ranges of adrenal hormones in patients with incomplete tumor resection.

\section{Long-term care of patients with hormone-secreting tumors}

In patients with complete tumor resection, evaluation of endocrine markers for disease recurrence should be performed every 3 months including cortisol (urinary free cortisol, evening salivary cortisol, or an overnight $1 \mathrm{mg}$ dexamethasone suppression test), androgens (dehydroepiandrosterone sulfate, androstenedione, testosterone), 17-hydroxyprogesterone and/or 11-deoxycortisol, based on pre-operative hormonal profile.

In patients with incomplete tumor resection, adjustment and/or institution of appropriate therapies are needed to maintain adrenal hormones within the physiological range and to adjust for changes in hormone secretion profiles. 


\section{Frequency of imaging}

An enhanced CT scan of chest and abdomen is recommended every 3 months for 1 year post-operatively, followed by repeat scans every 3-6 months for 5 years and at least annually thereafter if there is no evidence of tumor recurrence.

Bone scans and brain MRI should be based on symptoms.

PET is a promising tool that is currently under clinical investigation and should not yet be considered a standard of care in patient follow-up.

\section{Sensitivity of hormonal/humoral markers vs imaging findings}

No data are currently available to answer this question. All patients should be followed with anatomical imaging studies regardless of tumor hormone status.

\section{Adrenal cancer in children (Teinturier et al. 1996, Ribeiro et al. 2001)}

Moderators: Frank Worden, Paul Gauger

Lead Discussants: Ana Latronico, Raul Ribeiro

\section{Difference in the course of adrenal cancer in children and adults}

Tumors in children are more hormonally functional and there is a relatively low frequency of nonfunctioning tumors (incidentally discovered).

Virilization is the most frequent clinical manifestation $(70 \%)$, followed by mixed endocrine syndrome and Cushing's syndrome. Hyperaldosteronism and feminization occur rarely.

ACC in children may be associated with genetic cancer syndromes. Brazilian children with ACC tumors present the p53 mutation Arg337His in high frequency (78-97\%). Evidence of $\mathrm{LOH}$ was demonstrated in $90 \%$ of the children, including the p53 locus, as well as the entire chromosome 17.

The established criteria for distinguishing benign from malignant adrenocortical tumors in the adult population have not been helpful in predicting the biological behavior in the pediatric population. Patients with histologically malignant appearing tumors do well, often better than their adult counterparts.

Features associated with worse patient outcome are metastatic and recurrent disease and extension into periadrenal soft tissue and/or surrounding organs and invasion into the vena cava. Features associated with high probability of malignant behavior are:
- Histology

$>400 \mathrm{~g}$ (higher weight is predictive of patient outcome)

$>10.5 \mathrm{~cm}$ : Confluent necrosis with severe nuclear atypia and frequent and atypical mitoses

- Age: Younger children ( $<5$ years) have a significantly better prognosis than older children and adolescents whose tumors present similar behavior to adults

Molecular defects do not predict the biological behavior of the tumor.

\section{Recommended course of therapy}

- Surgical

Adrenalectomy

Adrenalectomy + nephrectomy

Adrenalectomy + partial hepatectomy

Adrenalectomy + splenectomy

Resection of intracaval thrombus

- Medical

Mitotane

Alternative chemotherapy regimens

- Radiation therapy

\section{Recommended follow-up}

Hormonal monitoring every 2 months in the first year, followed by monitoring every 4 months in the second year and every 6 months from then on.

Imaging studies are indicated only in the presence of hormonal abnormalities.

Local recurrence and isolated metastases should be resected.

\section{Data collection}

Moderators: Paul Gauger, David Schteingart

Lead Discussants: David Aron, Thomas Giordano

\section{Goals for developing an adrenal cancer registry and an inter-institutional database}

Development of an adrenal cancer registry and an interinstitutional database could meet multiple goals:

- They could facilitate the improvement of quality of care for patients with adrenal cancer by providing the data that underlie the evaluation and improvement of treatment regimens as well as the development and implementation of guidelines and protocols. 
- A registry can provide the data to answer epidemiological questions, e.g. the frequency of, causes of, and survival from adrenal cancer.

\section{Existing registries}

There are currently several adrenal cancer registries in Europe and the United States, many of which are multi-institutional. These include NISGAT (National Italian Study Group on Adrenal Tumors), COMETE (COrtico-MEdullo surrénale Tumeurs Endocrines), in France, and GANIMED (German Adrenal Network Improving Medical Research and Education), the University of Michigan, and others.

\section{Barriers to developing a database}

Barriers to merging data include different elements, different data definitions, and regulatory issues, among many others. However, some have already established a collaborative network: the European Network for the Study of Adrenal Tumors, which includes the three networks above and representatives from the UK, Greece and other countries.

However, there is precedent for collaboration for research and improvement in oncology. The Pediatric Oncology Group conducted sequential outcomes analysis of $>7000$ with rare forms of cancer (diagnoses from 1976 to 1989) from clinical trials, with constant eligibility and high participation rates. Collaboration gave statistical power and working from a unified database, significant improvement in outcome occurred in most of the diseases studied. Adrenal cancer is rare, but the group of clinicians dealing with such patients is broader than in pediatric oncology.

Ideally, there should be financial resources to convene an expert panel to design a registry and to ensure uniform data collection. However, certain steps can be taken now. For example, data dictionaries could be shared to assess the degree of commonality. Along with the creation of a Website outlining a minimum data set, this step could encourage movement towards standardization.

\section{Acknowledgements}

Supported in part by grants NIH-NCRR M 01-RR 00042 and the Millie Schembechler Adrenal Cancer Research Fund of the University of Michigan Comprehensive Cancer Center. The authors declare that there is no conflict of interest that would prejudice the impartiality of this work.

\section{References}

Arteaga E, Biglieri EG, Kater CE, Lopez JM \& Schambelan M 1984 Aldosterone-producing adrenocortical carcinoma. Preoperative recognition and course in three cases. Annals of Internal Medicine 101 316-321.

Bates SE, Shieh CY, Mickley LA, Dichek HL, Gazdar A, Loriaux DL \& Fojo AT 1991 Mitotane enhances cytotoxicity of chemotherapy in cell lines expressing a multidrug resistance gene (mdr-1/p-glycoprotein) which is also expressed by adrenocortical carcinomas. Journal of Clinical Endocrinology and Metabolism 73 18-29.

Bellantone R, Ferrante A, Boscherini M, Lombardi CP, Crucitti P, Crucitti F, Favia G, Borelli D, Boffi L \& Cappussotti L et al. 1997 Role of reoperation in recurrence of adrenal cortical carcinoma: results from 188 cases collected in the Italian Registry for Adrenal Cortical Carcinoma. Surgery 122 1212-1218.

Berruti A, Terzolo M, Pia A, Angeli A \& Dogliotti L 1998 Mitotane associated with etoposide, doxorubicin and cisplatin in the treatment of advanced adrenocortical carcinoma. Italian Group for the Study of Adrenal Cancer. Cancer 83 2194-2200.

Bodie B, Novick AC, Pontes JE, Straffon RA, Montie JE, Babiak T, Sheeler L \& Schumaker P 1989 The Cleveland Clinic experience with adrenal cortical carcinoma. Journal of Urology 141 257-260.

Bornstein SR, Stratakis CA, Chrousos GP 1999 Adrenocortical tumors: recent advances in basic concepts and clinical management. Annals of Internal Medicine $130759-771$.

Bradley E 1975 Primary and adjunctive therapy in carcinoma of the adrenal cortex. Surgery, Gynecology and Obstetrics 141507.

Brennan MF 1987 Adrenocortical carcinoma. CA: A Cancer Journal for Clinicians 37 348-365.

Cai W, Counsell RE, Djanegara T, Schteingart DE, Sinsheimer JE \& Wetring LL 1995 The metabolic activation and binding of mitotane in adrenal cortex homogenates. Journal of Pharmaceutical Sciences $\mathbf{8 4}$ 134-138.

Cibas ES, Medeiros LJ, Weinberg DS, Gelb AB \& Weiss LM 1990 Cellular DNA profiles of benign and malignant adrenocortical tumors. American Journal of Surgical Pathology 13 202-206.

Contreras P, Rojas A, Biagini L, Gonzalez P \& Massardo T 1995 Regression of metastatic adrenal carcinoma during palliative ketoconazole treatment. Lancet 2151.

Copeland PM 1984 The incidentally discovered adrenal masses. Annals of Surgery 116-122.

Dickstein G, Schechner C, Arad E, Best LA \& Nativ O 1999 Is there a role for low dose mitotane (o, p'-DDD) as adjuvant therapy in adrenocortical carcinoma. Journal of Clinical Endocrinology and Metabolism 84 1488-1489.

Didolkar MS, Bescher RA, Elias EG \& Moore RH 1981 Natural history of adrenal cortical carcinoma: a clinicopathologic study of 42 patients. Cancer $\mathbf{4 7}$ 2153-2161. 
Farge D, Chatellier G, Pagny JY, Jeunetaitre X, Plouin PF \& Corvol P 1987 Isolated clinical syndrome of primary aldosteronism in four patients with adrenocortical carcinoma. American Journal of Medicine 83 635-640.

Fetsch PA, Powers CN, Zakowski MF \& Abati A 1999 Antialpha-inhibin: marker of choice for the consistent distinction between adrenocortical carcinoma and renal cell carcinoma in fine needle aspiration. Cancer $\mathbf{8 7}$ 168-172.

Figueiredo BC, Stratakis CA, Sandrini R, Delarceda L, Pianovski MA, Giatzakis C, Young HM \& Haddad BR 1999 Comparative genomic hybridization analysis of adrenocortical tumors in childhood. Journal of Clinical Endocrinology and Metabolism 84 1116-1121.

Gaboardi F, Carbone M, Bozzola A \& Galli L 1991 Adrenal incidentalomas: what is the role of fine needle biopsy? International Urology and Nephrology 23 197-207.

Grayson GH, Moore S, Schneider BG, Saldivar V \& Hensel CH 1994 Novel germline mutation of the p53 tumor suppressor gene in a child with incidentally discovered adrenal cortical carcinoma. American Journal of Pediatric Hematology/Oncology 16 341-347.

Grondal S \& Curstedt T 1991 Steroid profile in serum: increased levels of sulphated pregnenolone and pregn-5ene-3 beta, 20 alpha-diol in patients with adrenocortical carcinoma. Acta Endocrinologica 124 381-385.

Gross MD, Shapiro B, Bouffard J, Glazer GM, Francis IR, Wilton GP, Kahfagi F \& Sonda LP 1988 Distinguishing benign and malignant euadrenal masses. Annals of Internal Medicine 109 613-618.

Haak HR, Hermans J, VandeVelde CJH, Lentjez EG, Goslings BM, Fleuren GJ \& Krans HM 1994 Optimal treatment of adrenal cortical carcinoma with mitotane: results in a consecutive series of 96 patients. British Journal of Cancer 69 947-951.

Hamper UM, Fishman EK, Hartman DS, Roberts JL \& Sanders RC 1987 Primary adrenocortical carcinoma: sonographic evaluation with clinical and pathologic correlation in 26 patients. AJR American Journal of Roentgenology 148 915-919.

Hogan T 1980 A clinical and pathological study of adrenocortical carcinoma; therapeutic implications. Cancer 452880.

Icard P, Chapuis Y, Andreassian B, Bernard A \& Proye C 1992 Adrenocortical carcinoma in surgically treated patients: a retrospective study on 156 cases by the French Association of Endocrine Surgery. Surgery 112 972-979.

Icard P, Goudet P, Charpenay C, Andreassian B, Carnaille B, Chapvis Y, Cougard P, Henry JF \& Proye C 2001

Adrenocortical carcinomas: surgical trends and results of a 253-patient series from the French Association of Endocrine Surgeons Study Group. World Journal of Surgery 25 891-897.

Jensen JC, Pass HI, Sindelar WF \& Norton JA 1991 Recurrent or metastatic disease in select patients with adrenocortical carcinoma: aggressive resection vs chemotherapy. Archives of Surgery 126 457-461.
Johnson DH \& Greco FA 1986 Treatment of metastatic adrenal cortical carcinoma with cisplatin and etoposide (VP-16). Cancer 58 2198-2202.

Juhlin C, Tornblom S, Rastad J, Bergstrom M, Bonasera T, Sundin A \& Langstrom B 1998 Differential diagnosis in adrenal gland tumors using PET an $11 \mathrm{C}$-metomidate. Nordisk Medicin 113 306-307.

Kasperlik-Zaluska A 1994 Impact of adjuvant mitotane on the clinical course of patients with adrenocortical carcinoma. Cancer 73 1533-1534.

Kasperlik-Zaluska A, Migdalska BM, Zgliczynski S \& Makowska AM 1995 Adrenocortical carcinoma: a clinical study and treatment results of 52 patients. Cancer $\mathbf{7 5}$ 2587-2591.

Khan TS, Imam H \& Juhlin C 2000 Streptozocin and o, $\mathrm{p}^{\prime}$-DDD in the treatment of adrenocortical cancer patients: long term survival in its adjuvant use. Annals of Oncology 11 1281-1287.

King D \& Lack E 1979 Adrenal cortical carcinoma; a clinical and pathological study of 49 cases. Cancer 44239.

Korobkin M, Lombardi TJ, Aisen AM, Francis IR, Quint LE, Dunnick NR, Londy F, Shapiro B, Gross MD \& Thompson NW 1995 Characterization of adrenal masses with chemical shift and gadolinium enhanced imaging. Radiology 197 414-418.

La Rocca RV, Stein CA, Danesi R, Jamis-Dow CA, Weiss GH \& Myers CE 1990 Suramin in adrenal cancer: modulation of steroid hormone production, cytotoxicity in vitro, and clinical antitumor effect. Journal of Clinical Endocrinology and Metabolism 71 497-504.

Leshinen Kallio S 1994 Positron emission tomography in oncology (Review). Clinical Physiology 14 329-335.

Lin SR, Lee YJ \& Tsai JH 1994 Mutations of the p53 gene in human functional adrenocortical neoplasms. Journal of Clinical Endocrinology and Metabolism 78 483-491.

Luton JP, Cerdas S, Billaud L, Thomas G, Gilhauge B, Bertagna X, Laudat MH, Louvel A, Chapius Y, Blondeau P et al. 1990 Clinical features of adrenocortical carcinoma, prognostic factors, and the effect of mitotane therapy. New England Journal of Medicine 3322 1195-1201.

Lynch HT, Katz DA, Bogard PJ \& Lynch JF 1985 The sarcoma, breast cancer, lung cancer and adrenocortical carcinoma syndrome revisited. Childhood cancer. American Journal of Diseases of Children 139 134-136.

MacFarlane DA 1958 Cancer of the adrenal cortex: the natural history, prognosis and treatment in the study of fifty five cases. Annals of the Royal College of Surgeons of England 23 155-186.

Magee BJ, Gattamaneni HR, Pearson D 1987 Adrenal cortical carcinoma: survival after radiotherapy. Clinical Radiology 38 587-588.

Martz F \& Straw JA 1977 The in vitro biotransformations of 1-(o-chlorophenyl)-1-(chlorophenyl)-2, 2-dichloroethane (o, p'-DDD) by dog adrenal mitochondria macromolecules. Drug Metabolism and Disposition 5 482-486. 
McNicol AM, Nolan CE, Struthers AJ, Farguharson MA, Hermans J \& Haak HR 1997 Expression of p53 in adrenocortical tumours: clinicopathological correlations. Journal of Pathology 181 146-152.

Medeiros LJ \& Weiss LM 1991 New development in the pathologic diagnosis of adrenal cortical neoplasms-a review. American Journal of Clinical Pathology 97 73-83.

Miyamoto H, Kubota Y, Shuin T \& Shiozaki H 1996 Bilateral adrenocortical carcinoma showing loss of heterozygosity at the p53 and RB gene loci. Cancer Genetics and Cytogenetics 88 181-183.

Munver R, Del Pizzo JJ \& Sosa RE 2003 Adrenal preserving minimally invasive surgery: the role of laparoscopic partial adrenalectomy, cryosurgery and radiofrequency ablation of the adrenal gland. Current Urology Reports 4 87-92.

Nader S, Hickey RC, Sellin RV \& Samaan NA 1983 Adrenal cortical carcinoma: a study of 77 cases. Cancer $\mathbf{5 2}$ 707-711.

Peix JL, Mancini F, Villard J \& Van Box Som P 1998 Malignant corticoadrenal tumors with vena cava extension. Is surgical resection justified? Annales de Chirurgie 52 357-363.

Percarpio B \& Knowlton AH 1976 Radiation therapy of adrenal cortical carcinoma. Acta Radiologica: Therapy, Physics, Biology 15 288-292.

Pineiro-Sanchez ML, Vaz A, Counsell RE, Sinsheimer JE \& Schteingart DE 1995 Synthesis of $\beta^{3} \mathrm{H}$-mitotane for use in a rapid assay for mitotane metabolism. Labeled Compounds \& Radiopharmaceuticals 36 121-127.

Pomier RF \& Brennan MF 1992 An eleven-year experience with adrenocortical carcinoma. Surgery 112 963-970.

Reincke M, Karl M, Travis WH, Mastorakos G, Allolio B, Linehan HM \& Chrousos P 1994 p53 mutations in human adrenocortical neoplasms; Immunohistochemical and molecular studies. Journal of Clinical Endocrinology and Metabolism 78 790-794.

Ribeiro RC, Sandrini F, Figueiredo B, Zambetti GP, Michalkiewicz E, Lafferty AR, De Lacerda L, Rabin M, Cadwell C, Sampaio G et al. 2001 An inherited mutation that contributes in a tissue specific manner to pediatric adrenal cortical carcinoma. PNAS 98 9339-9335.

Schlumberger M, Brugieres L, Gicquel C, Travagli JP, Droz JP\& Parmentier C 1995 5-Fluorouracil, doxorubicin and cisplatin as treatment for adrenal cortical carcinoma. Cancer 67 2997-3000.

Schteingart DE 1992 Treating adrenal cancer. Endocrinologist 2 149-157.

Schteingart DE 2000 Management approaches to adrenal incidentalomas. A view from Ann Arbor, Michigan. Endocrinology and Metabolism Clinics of North America 29 127-139.

Schteingart DE \& Homan D 2001 Management of adrenal cancer. In Adrenal Disorders, pp 231-247. Eds AN Margioris \& G Chrousos. Totowa, NJ: Humana Press.

Schteingart DE, Cash R \& Conn JW 1966

Aminoglutethimide and metastatic adrenal cancer.
Maintained reversal (six months) of Cushing's syndrome. Journal of the American Medical Association 1981007.

Schteingart DE, Sinsheimer JE, Counsell RE, Abrams GD, McClellan N, Djanegara T, Hines J, Ruangwises N, Benitez R \& Wotring LL 1993 Comparison of adrenalytic activity of mitotane and a methylated homolog on normal adrenal cortex and adrenal cortical carcinoma. Cancer Chemotherapy and Pharmacology 31 459-466.

Smith SM, Patel SK, Turner DA \& Matalonta 1989 Magnetic resonance imaging of adrenal cortical carcinoma. Urologic Radiology 11 1-6.

Sullivan M 1978 Adrenal cortical carcinoma. Urology 120660.

Teinturier C, Brugières L, Lemerle J, Chaussain JL \& Bougneres F 1996 Corticoserrénalomes de l'enfant: analyse rétrospective de 54 cas. Archives de Pédiatrie 3 235-240.

Terzolo M, Pia A, Berruti A, Osella G, Ali A, Carbone V, Testa E, Dogilotti L \& Angeli A 2000 Low dose monitored mitotane treatment achieves therapeutic range with manageable side effects in patients with adrenocortical cancer. Journal of Clinical Endocrinology and Metabolism 85 2234-2238.

Thompson NW 1983 Adrenocortical carcinoma. In Endocrine Surgery Update, pp 119-128. Eds NW Thompson \& AI Vinik.; Philadelphia, WB Saunders.

VanSeters AP \& Moolenaar AJ 1991 Mitotane increases the blood levels of hormone-binding proteins. Acta Endocrinologica 124 526-533.

Vassilopoulou-Sellin R, Guinee VF, Klein MJ, Taylor SH, Hess KR, Schultz PN \& Samaan NA 1993 Impact of adjuvant mitotane on the clinical course of patients with adrenocortical cancer. Cancer 71 3119-3123.

Venkatesh S, Hickey RC, Sellin R, Fernandez JF, Saaman NA 1989 Adrenal cortical carcinoma. Cancer 64 765-769.

Wajchenberg B, Albergaria PM, Medonca B, Medonca BB, Latronico AC, Campos Carneiro P, Alves VA, Zerbini MC, Liberman B, Carlos Gomes G et al. 2000 Adrenocortical carcinoma: clinical and laboratory observations. Cancer 711-736.

Weiss LM 1984 Comparative histologic study of 43 metastasizing and non-metastasizing adrenocortical tumors. American Journal of Surgical Pathology 8 163-169.

Weiss LM, Medeiros LJ \& Vickery AL 1988 Pathologic features of prognostic significance in adrenocortical carcinoma. American Journal of Surgical Pathology 13 202-206.

Williamson SK, Lew D, Miller GJ, Balcerzak SP, Baker LH \& Crawford ED 2000 Phase II evaluation of cisplatin and etoposide followed by mitotane at disease progression in patients with locally advanced or metastatic adrenocortical carcinoma. A Southwestern Oncology Study. Cancer 88 1159-1165.

Wood BJ, Abraham J, Hvizda JL, Alexander HR \& Fojo T 2003 Radiofrequency ablation of adrenocortical carcinoma metastases. Cancer 97 554-560. 
Wooten MD \& King DK 1993 Adrenal cortical carcinoma. Epidemiology and treatment with mitotane and a review of the literature. Cancer 72 3145-3155.

Yasuda S, Ide M, Fujii H, Nakahara T, Mochizuki Y,

Takahashi W \& Shohtsu A 2000 Application of positron emission tomography imaging to cancer screening. British Journal of Cancer 83 1607-1611.

Yun M, Kim W, Alnafisi N, Lacorte L, Jang S \& Alavi A 2001 18FDG PET in characterizing adrenal lesions detected on CT or MRI. Journal of Nuclear Medicine 42 1795-1799. 